\title{
Applying Lean, Green, and Six-Sigma Framework to Improve Exterior Construction Process in Saudi Arabia
}

\author{
Abdul-Aziz Banawi ${ }^{1}$ and Melissa Bilec ${ }^{2}$ \\ Received June 4, 2013 / Accepted January 20, 2014
}

\begin{abstract}
Over the last decade, Saudi Arabia has experienced significant economic increases as evidenced by the 30\% growth in its gross domestic product; furthermore, the construction industry has increased $10 \%$ in the same time period. ${ }^{1,2}$ Due to this significant growth, the construction industry is encountering issues related to construction quality resulting in significant waste and associated environmental impacts. In this research, we applied our previously developed framework that integrates three different methods - Lean, Green, and Six-sigma - to a residential construction complex in Saudi Arabia. Our aim of this case study was to explore the application of the framework in practice to glean quantitative results and further validate the framework. In the case study, we used the developed framework to identify a significant issue related to quality and delays - final completion of 53 residential units was delayed because of failed exterior buildings surfaces. We then used the framework to define the causes behind the defects via a field investigation of the 53 units. Of the defect, construction execution was responsible for $43 \%$ of the defect, $31 \%$ untrained workers, $19 \%$ unfavorable construction weather condition, with $7 \%$ accounting for other issues. A procedure was developed in concert with the construction manager and overall developer reducing the amount of rework and waste causes revealed by the field examination and the framework. Although two steps were added to the original construction process to overcome waste causes, still save a lot of resources and reduces environmental impact. In summary, we found that the Lean, Green, Six-sigma framework increased productivity, quality, and reduced waste.
\end{abstract}

Keywords: Saudi Arabia Construction Industry; Construction Processes Improvement; Value Stream Mapping; Life Cycle Assessment; Six-Sigma

\section{INTRODUCTION}

The construction industry has a major impact on economic growth. In developing countries such as Saudi Arabia, the construction sector is essential to short- and long-term economic growth. In 2010 the construction industry accounted for $11 \%$ of Saudi Arabia's Gross Domestic Product (GDP) at $\$ 300$ billion[1]. Saudi Arabia's GDP growth was the highest the country has experienced in the last several years[2]. Many projects in various sectors have been constructed with more projects in the planning phase. Some current construction projects include $36,800 \mathrm{~km}$ of new roads, new airports, and additional berths in ports[3]. Unfortunately, the rise in construction activity has also lead to a host of construction issues - shortages of equipment, trained workers, and materials; sub-prime scheduling of activities during significantly higher temperature; and rejection of defective products and processes.

For many countries, environmental protection and sustainable development are integral aspects to long-term strategic planning, legislation, and executive orders. While a host of environmental issues exists, some of the most pressing ones include, non-renewable energy usage, climate change, waste generation, water quality and quantity, and available natural resources, all of which are exacerbated by increasing global population[4]. The construction industry is a primary consumer for natural resources[5]. In Saudi Arabia, for example, the demand for cement reached about 36.7 million tons, one third of US cement consumption in 2008[1, 6].

Due to high construction activity, and low-quality issues, the Saudi construction industry is faced with the dual issue of waste management and use of natural resources. Even though a significant portion of the municipal waste stream in Saudi Arabia is from construction, the government exercises minimal effort. Furthermore, Saudi construction companies have an unclear understanding of the problem. From an examination of various sources including waste management facilities, municipalities, and construction companies, there is a lack of data and information regarding quantities, composition, and sources of construction waste in Saudi Arabia[7-10].

To address this problem, we applied our framework that integrates three different methods-Lean, Green, and Sixsigma - in a systematic approach, with the goal of reducing waste and therefore the associated environmental impacts of the construction process[11]. Our aim was to illustrate via a residential development project in Saudi Arabia that all three methods in concert have the potential to minimize impacts generated by construction activities while improving quality.

\section{BACKGROUND AND LITERATURE REVIEW}

\section{A. Method Background}

\footnotetext{
${ }^{1}$ Doctoral Candidate, Civil and Environmental Engineering, University of Pittsburgh, 153 Benedum Hall, Pitsburgh, PA 15261 - USA, aab64@ pitt.edu

${ }^{2}$ Assistant Professor, Civil and Environmental Engineering, University of Pittsburgh, 153 Benedum Hall, Pitsburgh, PA 15261 - USA, mbilec@ pitt.edu (*Corresponding Author)
} 
This research integrates three methods: Lean to reduce waste, green to assess the environmental impact, and SixSigma to improve quality.

Lean's main purpose is to eliminate all forms of waste[12]. Waste is usually defined as any step or action in the process that does not provide value to the customer[13]. There are seven different types of waste, including moving products, materials, or equipment; overproduction, waiting; defects; inventory; motion; and extra processing[14]. Lean has several tools to help identify waste, for example, Value Stream Mapping (VSM). VSM is a visual tool that graphically organizes all elements of a process such as, a description of the job procedure, parties involved in the process to deliver the job, time of the process in progress and the time of the process on hold, and inventories such as materials, equipment, and workers that the process consumes[15, 16].

While a host of definitions exist for 'greening,' the definition used in this work is that greening minimizes the environmental impact of a product, process or service. A method for quantifying greening efforts is Life Cycle Assessment (LCA). LCA is a tool used to calculate that environmental impacts of a product, process or service through its entire life cycle, starting from extraction of the material and energy used in the production process, to acquisition, to product use, and finally to disposal. LCA is a four-step procedure including goal and scope definitions, life-cycle inventory (LCI) analysis, life-cycle impact assessment (LCIA) and interpretation[17]. LCA is a valuable approach, which helps in decision making and creating opportunities for improvements within processes.

Six-sigma is a methodology that focuses on customer (internal or external) needs, data, statistical analysis, continuing improvement, and reinventing business. Sigma refers to the amount of inconsistency or variance occurring in the process, and Six-sigma equates in statistics to 3.4 defects per millions opportunities. The Six-sigma method has many benefits, including identifying and eliminating sources of variation, extending success, setting performance goals for all parties, enhancing value to customers, and executing strategic change[18]. DMAIC is a Six-Sigma approach involving five steps: Define, Measure, Analyze, Improve, Control. A number of tools and methods can be used in each of the five step[19].

In this paper, two Six-sigma tools are used - Pareto chart and Process improvement - selected due to their ability to analyze and improve processes. These tools are used to identify the sources of waste and variations in processes. Process improvement main purpose is to change current processes to see the effect on process outputs. The tool, Process improvement is commonly used in the improvement phase step of DMAIC as an aid in selecting the most effective solutions. In the building industry, there are three major steps to apply Process improvement tool: (1) define an objective, (2) define the variables that will be controlled, and (3) choose the design that is compatible with the objective (Kolarik 1995). ${ }^{20}$ Vilfredo Pareto, an economist who lived in Italy during the nineteenth-century developed a theory based on his observation calls (80-20). Pareto noticed that $80 \%$ of the country wealth was controlled by $20 \%$ of the population. Later this concept was applied to causes of quality failures by Dr. Juran. They stated that $20 \%$ of the causes account accounts for $80 \%$ of the failures. In general the Pareto can help identifying the most important effects and causes and stratify the available data so process improvement efforts can be prioritized[20].

\section{B. Literature Review}

The nature of the construction industry is complex. Construction projects need to be expertly managed to not only consider budgets and schedules, but also quality and environmental impacts[21, 22]. Lean, Green, and SixSigma are different methods that have been often used independently to address quality, waste, and environmental impacts in construction. Previous studies have addressed improving the quality of construction processes and strategies for the reduction of construction waste[23-26]. For example, Serpell and Alarcun[27] created a framework for improving construction processes through a set of structured activities and tools to help increase quality. Wang[28] in 2008 created an automated quality management system that helps gather, filter, manage, monitor and share quality data between different crews involved during construction. This system was able to enhance information flow, saving cost, increasing speed and improving quality. Arditi and Gunaydin[29] addressed the importance of process quality to construction companies. One way to improve process quality is through Total Quality Management (TQM), which has shown great benefits when applied in manufacturing industries. The successful implementation of TQM in the construction industry requires a commitment to quality from both management and workers. In addition the implementation of technological advances in design and construction, full knowledge of assembly process amongst workers have been identified as factors influencing total industry productivity (TIP) for construction[30]. The impact of effective pre-construction planning on the reduction of waste was highlighted in a survey of high rise construction projects in Hong Kong which showed that execution of work orders with incomplete contract documentation can result in the loss of quality in several areas such as frequent variation in design, inaccurate material orders, as well as delivery scheduling difficulties[31].

With respect to the use of Lean strategies to identify waste and construction, Garrett and Lee[32] analyzed the submittal and review processes of a typical construction project and concluded that incomplete or deficient documentation raised problems during construction; through the application of Lean tools to reducing non-value added activities, measureable reductions in both process and lead times were obtainable. Lapinski, Horman et al[33] examined Toyota's successful implementation of Lean methodologies to minimize costs in construction, specifically how lean can reduce the high initial expense of green buildings by eliminating process waste. At specific process level, Pasqualini and Zawislak[34] applied Value Stream Mapping (VSM) to masonry construction to 
highlight all associated waste sources including extra inventories and delays; however, they did not identify the causes of proposed solutions. Another study by Yu, Tweed et al[35] found that poorly managed production flows result in significant construction waste, and then used VSM to analyze and restructure the system to minimize waste.

With respect to Greening, Life Cycle Assessment has been used in previous studies to quantify the environmental impacts of construction. A life-cycle study developed by Bilec, Ries et al[36-37] found that the construction phase, though not as significant as the use phase, is important, highlighting the generation of particulate matter (PM) emissions during construction. Guggemos and Horvath[38] utilized LCA to examine strategies for reducing environmental impact of on-site construction activities, particularly minimizing and reusing temporary materials during construction. They also found that using well-maintained or new construction equipment will improve the environmental impact of the construction phase. Aimed at better informing decision makers seeking to add environmental quality and sustainable development to project goals, a study by Sharrard, Matthews et al[39] developed an input-output LCA estimating the comprehensive environmental effects of construction processes. Also, a study by Li, Zhu et al[40] applied process LCA to work breakdown structures to help decision makers have a clearer understanding of the environmental impact of the material and equipment brought to the project during the construction phase.

With respect to quality of construction, Six-Sigma is a quantitative methodology that establishes definitive improvement goals to reduce process variability in current construction operations. Six-Sigma was combined with Lean in Han, Chae et al[41] study and shows a great benefits. Six-Sigma evaluates the quality of the current operation and quantify the goals of improvement for targeted work flow so as to control the critical sources of variability. Defects Per Million Opportunities (DPMO) is the Six-Sigma process-performance metric applied by Pheng and Hui[42] to internal finishing process for a residential construction project. The low process performance-2 sigma-encouraged the contractor to supervise its ongoing building projects more closely, better ensuring that the level of workmanship for the internal finishes complies with overall quality standards. A model which helped enhance interactions between project teams, reduced project delays and provide a structured process-improvement strategy, DMAIC, was used by Stewart and Spencer[43] to improve the productivity of beam construction process for a railway station. Moreover DMAIC provides a solid procedure for gathering of information, and enabling process quality improvement. Despite a fairly robust body of literature in these three distinct methods, there is a gap in the research combining Lean, Green, and Six-Sigma into one framework to comprehensive improve the construction processes impacts generated by construction activities while improving quality.

\section{METHOD}

The overall framework was based on Six-sigma's, Define, Measure, Analyze, Improve, Control, (DMAIC). Previously discussed in . To briefly summarize, Steps $1 a$ and $1 b$, Define and Measure, after selecting a construction process for evaluation, concurrently apply both Lean (VSM) and Green (LCA) to determine if waste is generated in the process and then to quantify the environmental impacts of the waste. Steps $2 a$ and $2 b$, Analyze and Improve, If the process generates waste, then one or more appropriate Six-sigma tools is selected and applied to eliminate or reduce waste. Essentially, the framework contains Six-sigma tools nested within Step 2. For example, in this research Pareto Chart and Process improvement were the selected Six-sigma tools, however any Six-sigma tool(s) could be executed for use in Step 2 based on the case needs. Step 3, Control, Re-evaluate using Lean (VSM) and Green (LCA) to determine the extent of waste reduction. Each step is illustrated below in the illustrative case study.

\section{A. Case Study}

A case study was applied to improve the construction processes for a residential complex in Madinat Yanbu AlSinaiyah (MYAS), Saudi Arabia and to illustrate the functionality of the framework. MYAS is one of two industrial cites established in Saudi Arabia to support the oil industry. MYAS is the western destination of oil and gas pipelines that start from the production area in the east of the Kingdom and is considered the largest port for exporting oil to the red sea. MYAS is an attractive business destination to many major oil investors from inside and outside the country. Therefore, construction in this area is a high priority on the Royal Commission for Industrial Yanbu's (RCIY) agenda with aim to provide services required by residents such as, housing, industrial, health, education, recreational and public services.

Prior to applying the framework, onsite inspection was conducted - a total of two months June to August 2012. During the on-site inspection and collection phases, the framework was introduced and explained to the both the construction project manager and the RCIY project manager. On-site inestgation of all study units for completed to identify major issues of project delay and rejection.

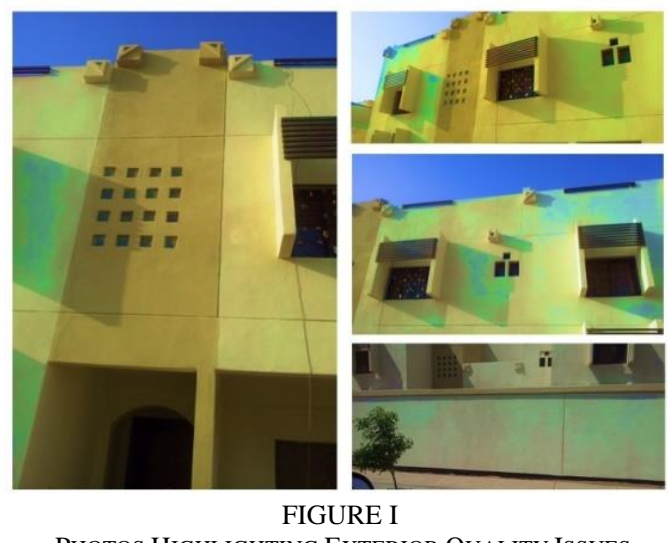

Photos Highlighting EXTERIOR QUALITY ISSUES 
The framework was then applied to help analyze and improve the root causes behind the appearance of painting blistering on buildings surfaces, shown in Fig. 1. 53 residential units totaling 498, 664 sf were investigated in this case study. The exterior painting construction process evaluated in this case study consisted of three simple steps: (1) applying cement plaster, (2) applying primer sealer, and (3) applying paint.

\section{RESULTS AND DISCUSSION}

To explain the implementation of the framework, we view each step in the process as important part of the results:

\section{A. Step 1a, Value Stream Map}

For Step la, a Value Stream Map (VSM) was developed in order to identify, for each step of the exterior painting processes where waste occurred (see Fig. 2). The VSM was organized into four major elements: (A) project management, (B) the exterior painting construction process, (C) supplier, and (D) customer. The VSM systematically illustrates the relationships between the actors, data flow, and logistics. As illustrated in the VSM, the painting construction process consisted of three steps, with the duration of 53-55 days. Lead/total time was a combination of Non- Value Added Time (NVA/T) or the time the process was on hold; and Value-Added Time (VA/T), the time the process was in progress. The NVA/T was 4 to 6 business days while the VA/T was 49 business days; furthermore the VSM explains the resources the process consumed including labor hours, materials and equipment. Finally, the VSM shows that units were rejected due to the appearance of painting blistering on the building surfaces.

\section{B. Step 1b, Greening}

For Step $1 b$, Greening, LCA was used to evaluate the environmental impacts of the exterior painting construction process. The LCA system boundary for the exterior painting construction process includes raw materials extraction and manufacturing; transportation of equipment, materials, and workers to and from the site; and equipment usage on site. LCA was used to quantify the original process, and subsequently, the modified/improved process to understand the reduction in the environmental impacts. The Tool for the Reduction and Assessment of Chemical and Other Environmental Impacts (TRACI 2 V3.01) was used to perform the life cycle impact assessment [44]. The life cycle inventory data used is shown in Table 1.

The comparative LCA results of the exterior paint process for nine environmental impact categories are shown in Fig. 3 for three process phases: Materials, Equipment manufacturing and combustion, and Transportation. Of the general environmental impacts, materials exhibited the highest share of impacts in all of the categories except for Ozone depletion, where equipment manufacturing and combustion was the highest. Both Equipment manufacturing and combustion and transportation was second in four categories. For instance Equipment manufacturing and combustion came second in terms of Acidification, Carcinogenic, Noncarcinogenic and Ecotoxicity, while transportation was the second highest in global warming, respiratory, eutrophication, and smog.

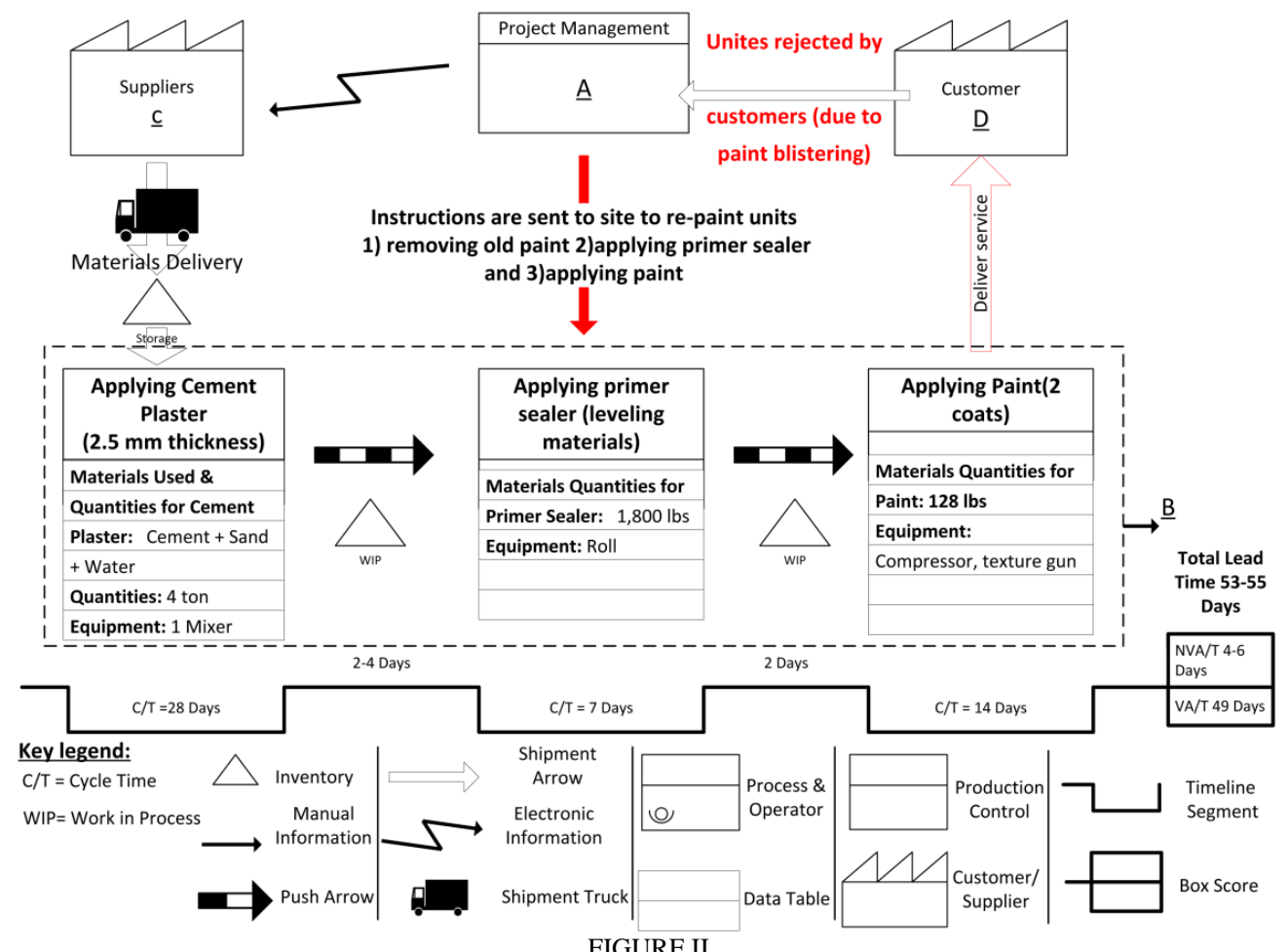

Value Stream Map (VSM) of CASe Study Exterior Painting Process 
TABLE I

LIFE CYCLE INVENTORY, DATA SOURCES AND REMARKS FOR EXTERIOR PAINTING PROCESS

Note:

Original Process consists of: 1) applying cement plaster, 2) applying primer sealer, and 3) applying paint.

Modified Process consists of: 1) pre-plastering, 2) applying cement plaster, 3) cleaning surfaces, 4) applying primer sealer, and 5) applying paint.

Rejected Process consists of: 1) applying cement plaster, 2) applying primer sealer, 3) applying paint, 4) Removing old paint, 5) applying primer sealer,6) applying paint.

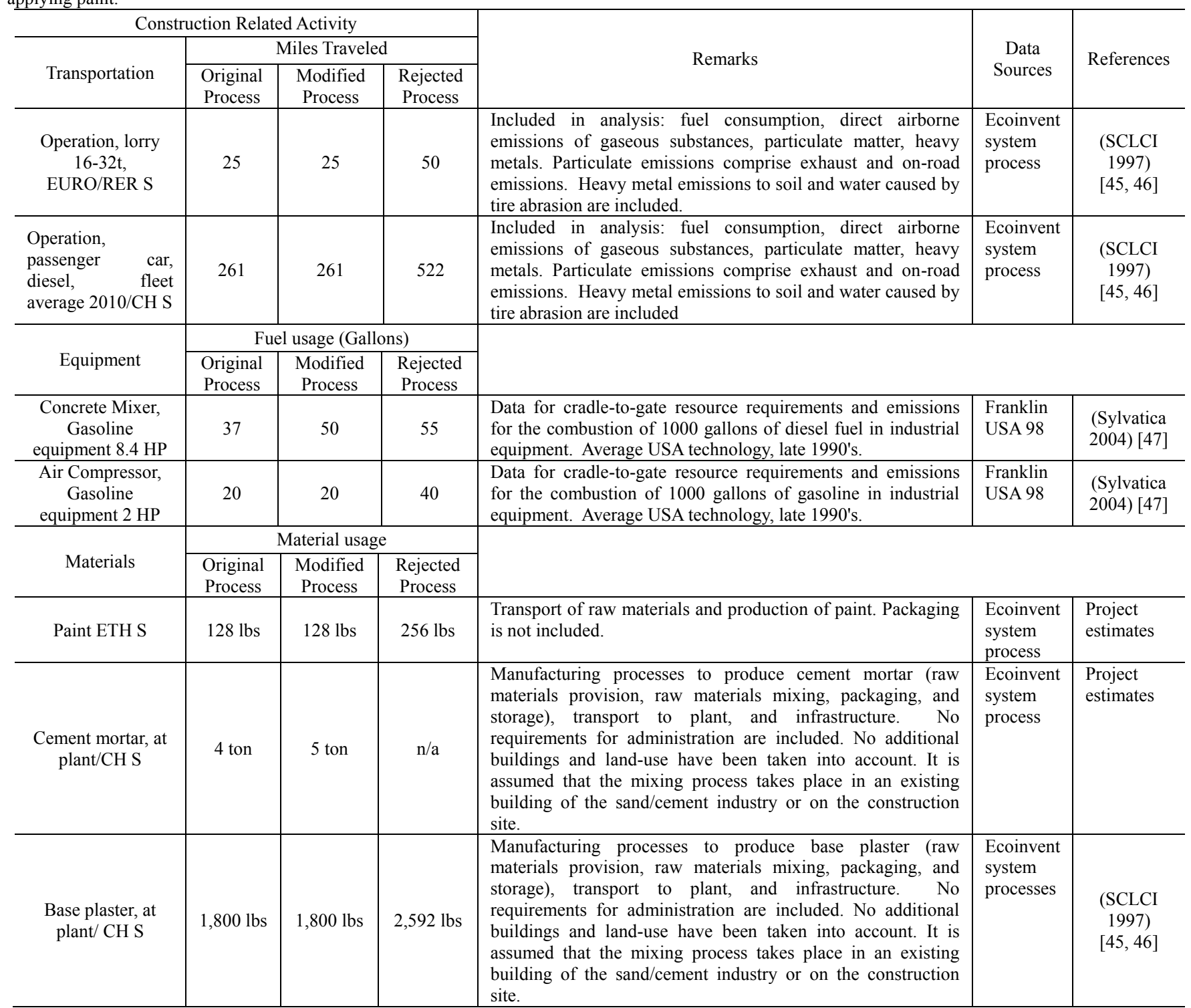

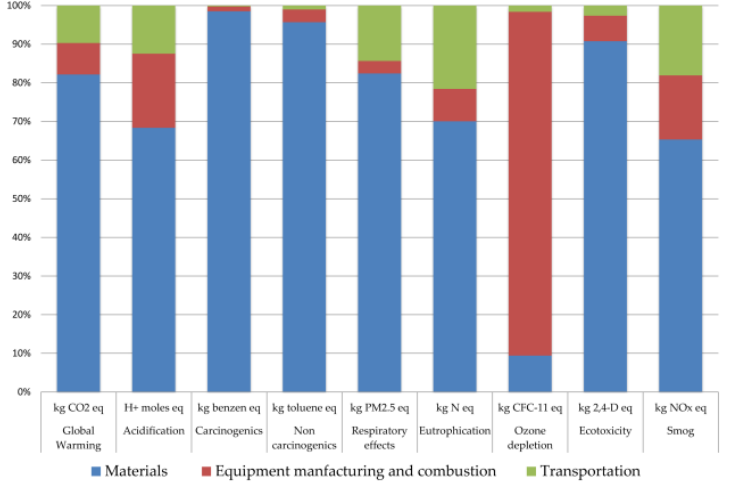

FIGURE III

LIFE CYCLE ENVIRONMENTAL IMPACTS FOR THE ORIGINAL EXTERIOR PAINTING PROCESS
For a closer analysis of the overall LCA results, cement manufacturing is a significant contributor to environmental impact from materials while paint came second as is shown in Fig 4.

\section{Step 2, Analyze and Improve}

For Step 2, Analyze and Improve, the Six-sigma process improvement method was implemented using a Pareto chart to analyze and identify the most commonly occurring causes that led to blistering. Then, Process improvement was used to improve and create an alternative process that could minimize the variables' occurrence. In order to identify the variables causing blistering, an evaluation of 53 residential units was accomplished. Out of these 53 units, only 10 units exhibited minimal blistering while the remaining 42 units 
had extensive blistering. A data sheet and site observations were used to collect data for the Pareto chart, see supplementary data. Identifying major causes for blistering was time intensive task. The units were carefully examined with the contractor project manager and the RCIY project manager. Different parties were asked for their feedback regarding the low quality of the painting including, superintendents, project engineers, foremen, and workers. After finalized data collected from the site, four major factors of blistering were observed from the site: inadequate application $(43 \%)$, untrained workers $(31 \%)$, unfavorable weather conditions (19\%), and others (7\%), see Fig 5.

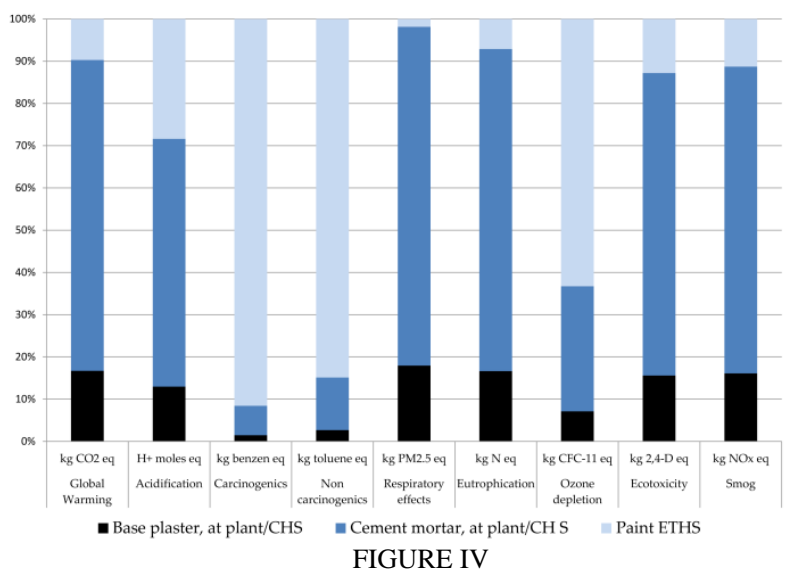

LIFE CYCLE ENVIRONMENTAL IMPACTS FOR MATERIALS CONSUMED FOR THE EXTERIOR PAINTING PROCESS

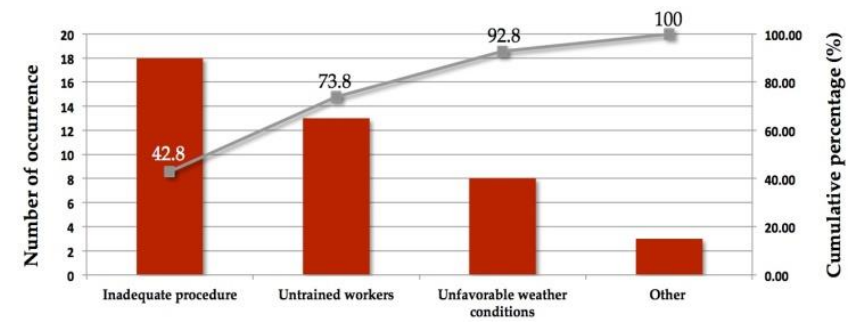

FIGURE V

PARETO CHART WITH FACTORS THAT GENERATE WASTE ACCORDING TO THE FIELD INVESTIGATION OF 53 UNITS FOR THE EXTERIOR PAINTING PROCESS

The Process improvement method was then used in order to improve the original process and to reduce the defect's causes revealed by the Pareto chart. The main objective of the modified process was to eliminate or minimize the occurrence of blistering. Therefore, all four factors were considered at the time the modified process was created. The modified process includes two additional steps: (1) preplastering, (2) applying cement plaster, (3) cleaning surfaces, (4) applying primer sealer, and (5) applying paint with adequate wait time. The pre-plastering step involves adding bonding materials to minimize humidity transfer to surfaces. Humidity (under cause, unfavorable weather conditions) was shown to be a major cause of the blistering. The humidity resulted from the fact that more water was added to concrete during construction because of the high temperature to slow the curing process. The other new step was cleaning the surface before applying the primer. Both processes are obvious, yet neglected, solutions. Due to the climate of the area, dust is a major issue, especially in the summer season. The dust particles co-mingle with the paint, contributing to blistering. Lastly, a recommendation of increasing the waiting time from 2 to 4 days was recommended before the last step of applying paint.

Fig. 6 shows the current VSM for modified process, addressing the additional two steps and all other data related to the exterior painting process. In collaboration with the construction management team, the modified process was successfully applied to two residential units. Both units were carefully examined and both showed no signs of blistering (see Fig 7).

\section{Step 3, Control}

Finally Step 3, Control, retrospectively evaluates the achieved process performance as well as techniques and strategies implemented in order to develop improved procedures for better performance in the future. Step 3 is essential to the framework: this step is responsible for maintaining consistent successful performance and for continuous improvement.

The modified process was able to deliver a consistent construction process, and one designed to overcome unfavorable weather conditions and changing labor force. While the modified process did require more time and more resources than the original process, the modified process was the environmentally preferable option when compared to original process plus rejected work. The rejected process process' environmental impact includes the original process environmental impact plus the environmental impact generated from repeating two steps: applying base plaster and applying paint (see Table 2).

TABLE II

LIFE CYCLE ENVIRONMENTAL IMPACTS AND TIME DURATION OF THE ORIGINAL PAINTING PRocess, MOdified PROCESS, AND REJECTED PROCESS

\begin{tabular}{|c|c|c|c|c|}
\hline $\begin{array}{l}\text { Impact Cate } \\
\text { gory }\end{array}$ & Unit & $\begin{array}{c}\text { Original } \\
\text { Process (OP) }\end{array}$ & $\begin{array}{c}\text { Modified } \\
\text { Process } \\
(\mathrm{MP})\end{array}$ & $\begin{array}{c}\text { Rejected Process } \\
\text { (Including OP) }\end{array}$ \\
\hline $\begin{array}{l}\text { Global War } \\
\text { ming }\end{array}$ & $\mathrm{kg} \mathrm{CO} 2 \mathrm{eq}$ & 1291 & 1510 & 1634 \\
\hline $\begin{array}{l}\text { Acidificat- } \\
\text { ion }\end{array}$ & $\mathrm{H}+$ moles eq & 194 & 222 & 276 \\
\hline $\begin{array}{c}\text { Carcinog- } \\
\text { enics }\end{array}$ & $\mathrm{kg}$ benzen eq & 9 & 9.6 & 18 \\
\hline $\begin{array}{c}\text { Non carcino } \\
\text { ge-nics }\end{array}$ & $\mathrm{kg}$ toluen eq & 29409 & 30505 & 54266 \\
\hline $\begin{array}{l}\text { Respirato- } \\
\text { ry effects }\end{array}$ & $\mathrm{kg}$ PM2.5 eq & 0.5 & 0.6 & 0.64 \\
\hline $\begin{array}{l}\text { Eutrophi- } \\
\text { cation }\end{array}$ & $\mathrm{kg} \mathrm{N} \mathrm{eq}$ & 0.26 & 0.3 & 0.34 \\
\hline $\begin{array}{c}\text { Ozone } \\
\text { depletion }\end{array}$ & kg CFC-11 eq & 0.001 & 0.001 & 0.002 \\
\hline Ecotoxicit-y & $\mathrm{kg} \mathrm{2,4-D} \mathrm{eq}$ & 681 & 802 & 837 \\
\hline Smog & kg NOx eq & 2.7 & 3 & 4 \\
\hline \multicolumn{2}{|c|}{ Number of steps } & 3 & 5 & 5 \\
\hline \multicolumn{2}{|c|}{ Duration (Days) } & $53-55$ & $67-71$ & 72 \\
\hline
\end{tabular}




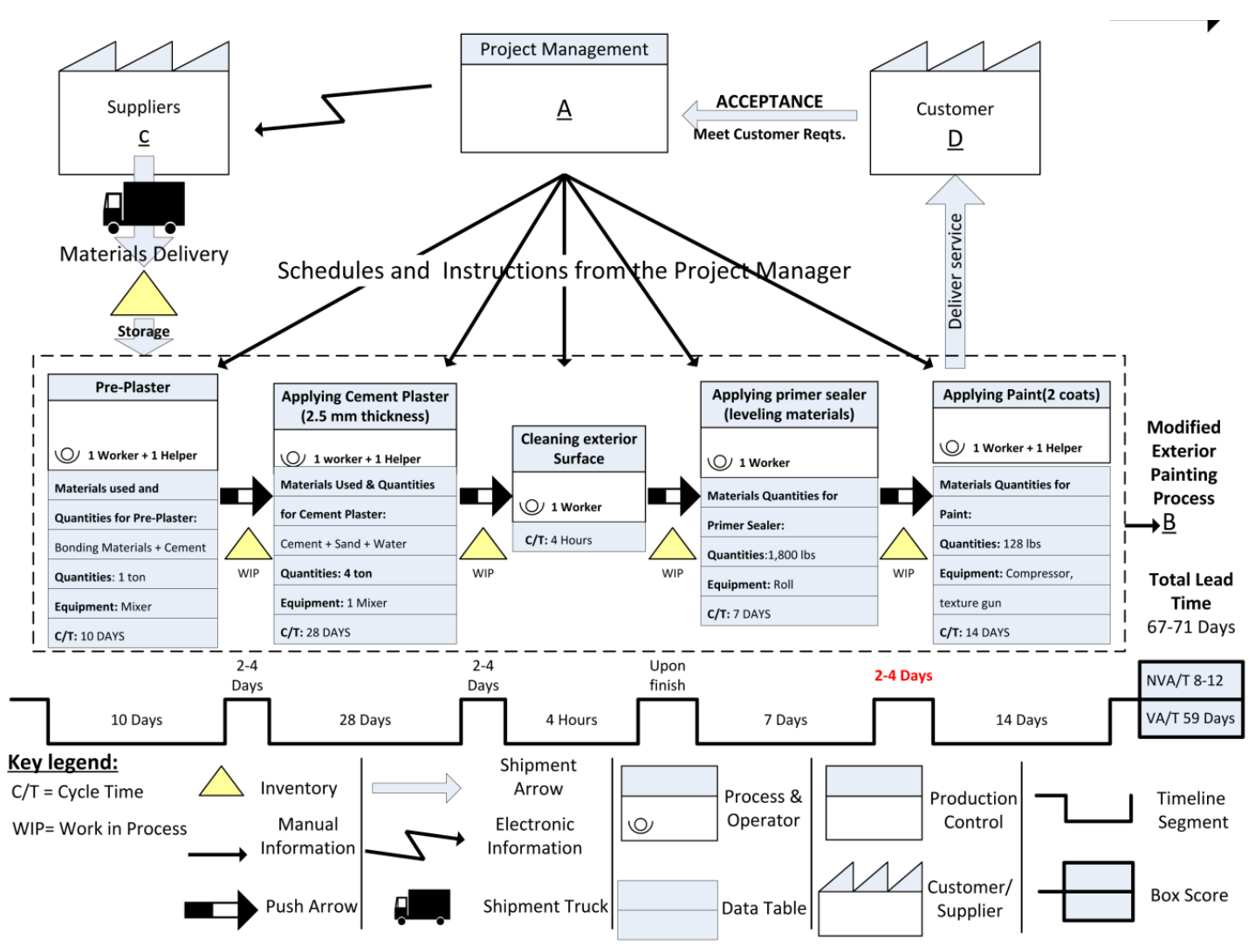

FIGURE VI

Modified VAlue Stream MAP (VSM) FOR THE EXTERIOR PAinting PROCESS

To recap, this framework enabled us to apply the concept of DMAIC to the construction phase to improve the process. The sequence of steps starts with evaluating a chosen process, identifying the waste generated during the process, and measuring its impact. Then, through the use of Sixsigma tools, we were able to identify possible reasons for the generation of the waste, and find suitable solutions to implement. Finally, the success of these solutions is monitored and revised business processes established to maintain improved performance.

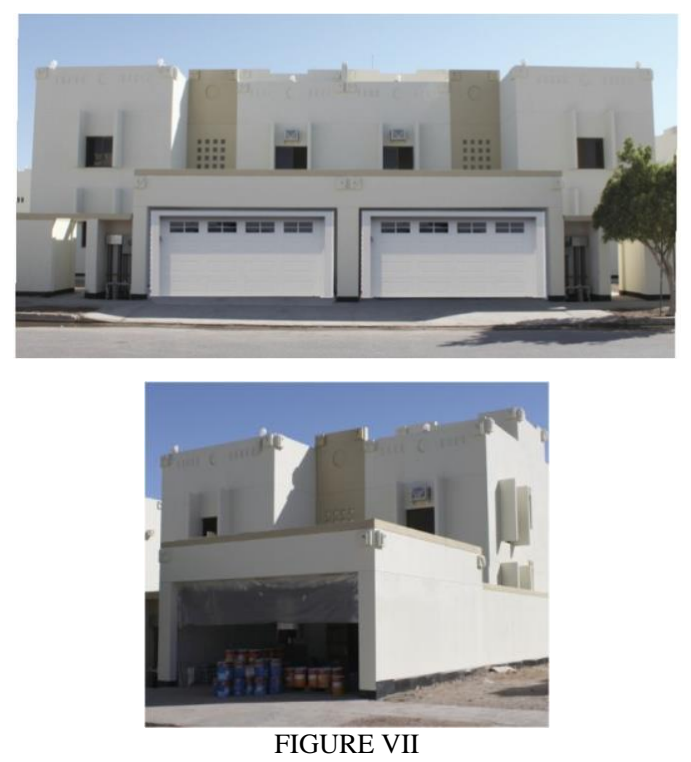

EXAMPLES OF THE MODIFIED PAINTING PROCESS OUTCOMES

\section{CONCLUSION}

Saudi Arabia is experiencing a boom in the construction industry, yet it is facing many challenges that could impact the industry's environmental performance. This paper explains a previously developed framework that can be used to identify and reduce waste during construction processes by integrating three methods: Lean, Green, and Six-Sigma. A case study of applying exterior painting construction process in a residential complex in Saudi Arabia was implemented to further illustrate and validate the framework. A major defect, blistering, was identified. The associated environmental impact of the painting construction process was analyzed using TRACI impact categories. The consumption of materials was the highest contributor to most categories including Global Warming, Acidification, Carcinogenic, Non Carcinogenic, Respiratory Effects, Eutrophication, Ecotoxicity, and Smog. Potential causes of waste were identified, then validated and ranked, using a Pareto Chart. The root causes responsible for the blistering occurring during the construction phase were identified as "inadequate procedure" accounting for $43 \%$, "untrained workers" at $31 \%$, "unfavorable weather conditions" at $19 \%$, and "others" at 7\%. A modified process was developed to eliminate potential causes by applying the Design of Experiment method. The modified process was then implemented on two residential units for validation. The modified process was able to deliver units that are blistering less.

In the future the Lean Green, Six-Sigma framework will be developed to be part of the quality inspection for 
buildings during construction. To achieve that, the framework should take less time and the efforts tool, yet should deliver the desire results. Also the successful attempts in this study will be introduced to several organizations in Saudi Arabia to encourage industry to consider other aspects during construction such as the environmental impacts.

\section{ACKNOWLEDGMENT}

The authors wish to thank the Ministry of Higher Education, Saudi Arabia for the support and efforts provided through King Abdullah Scholarships Program. Also the authors would like to thank the Royal Commission of Industrial Yanbu for their help providing data for the case study in this research.

\section{REFERENCES}

[1] Saudi National Commercial Bank, "In Focus Report, Saudi Construction Sector Review", Jeddah, Saudi Arabia, 2011.

[2] Saudi Arabia - Ministry of Finance, "Recent Economic Developments and Highlights of Fiscal Years 1431/1432 (2010) \&1432/1433 (2011)", Ryadh, Saudi Arabia, 2011.

[3] Saudi Arabia - Ministry of Economy and Planning, "Saudi Arabia: Economic Indicators (2004 - 2011)", Riyadh, SA, 2012.

[4] U.S. Environmental Protection Agency, "Buildings and their Impact on the Environmental: A Statistical Summary”, Washington, DC, 2009.

[5] U.S. Environmental Protection Agency, "Construction and Demolition Materials Amounts", Washington, DC: 1-27, 2003.

[6] Portland Cement Association, "Cement Industry Overview", http://www.cement.org/econ/industry.asp.

[7] M. Al-Jarallah, "Construction Industry in Saudi Arabia", Journal of Construction Engineering and Management, vol. 109, no. 4, pp. 355$368,1983$.

[8] S. Assaf, S. Al-Hejii, "Causes of Delay in Large Construction Projects ", International Journal of Project Management, vol. 24, no. 4, pp. 349$357,2006$.

[9] A. Al-Sudairi, "Evaluating the Effect of Construction Process Characteristics to the Applicability of Lean Principles ", Construction Innovation, vol. 7, no. 1, pp. 99-121, 2007.

[10] M. Al-Nagadi, "Concrete Construction Industry-Cement Based Materials and Civil Infrastructure", Paper presented at the International Workshop - Cement Based Materials and Civil Infrastructure Pakistan, 2007.

[11] A. Banawi, M. Bilec, "A Framework to Improve Construction Processes: Integrating Lean, Green, and Six-Sigma", International Journal of Construction Management (Under review), vol. 14, no. 1, 2013.

[12] O. Salem, J. Solomon, M. ASCE, A. Genaidy, I. Minkarah, M. ASCE, "Lean Construction: From Theory to Implementation", Journal of Management in Engineering, vol. 22, no. 4, pp. 168-175, 2006.

[13] W. James, D. Jones, "Lean Thinking: Banish Waste and Create Wealth in Your Corporation New York", NY, FREE PRESS, 2003.

[14] T. Ohno, "Toyota Production System", $1^{\text {st }}$ ed, Tokyo, Japan Diamond, Inc., 1990.

[15] N. Sayer, B. Williams, "Lean for Dummies WILEY", 2007

[16] R.J. Arbulu, I.D. Tommelein, "value stream analysis of construction supply chains: case study on pipe supports used in power plants", International Group for Lean Construction University of California, 2002.

[17] International Organization for Standardization. "Iso 14040 Environmental Management - Life Cycle Assessment Principles and Framework" Switzerland, 2006

[18] Y. Kwak, F.T. Anbari, "Benefits, Obstacles, and Future of Six Sigma Approach.", Technovation, vol. 26, no. 56, pp. 708-15, 2006.

[19] P. Pande, R. Neuman, R. Cavanagh, "The Six Sigma Way: How Ge, Motorola, and Other Top Companies Are Honing Their Performance" $1^{\text {st }}$ ed, New York: McGraw-Hill, 2000.

[20] J.W. Kolarik, "Creating Quality", $1^{\text {st }}$ ed, New York McGraw-Hill, 1995.
[21] G. Howell, G. Ballard, "Implementing Lean Construction: Understanding and Action ", 1998.

[22] C. Formoso, L. Soibelman, C. Cesare, E. Isatto, "Material Waste in Building Industry: Main Causes and Prevention", Journal of Construction Engineering and Management, vol. 128, no. 4, pp. 316-25, 2002.

[23] B. Bossink, H. Brouwers, "Construction Waste: Quantification and Source Evaluation", Journal of Construction Engineering and Management, 1996.

[24] W.G. Chase, "Improving Construction Methods: A Story About Quality", Journal of Management in Engineering, vol. 14, no. 3, pp. 30, 1998.

[25] L. Ekanayake, G. Ofori, "Construction Material Waste Source Evaluation.", Paper presented at the Strategies for a Sustainable Built Environment, 2000.

[26] D. Love, J. Edwards, Z. Irani, D. Walker, "Project Pathogens: The Anatomy of Omission Errors in Construction and Resource Engineering Project.", Engineering Management, IEEE Transactions on, vol. 56, no. 3, pp. 425-35, 2009

[27] S. Alfredo, L.F. Alarcun, "Construction Process Improvement Methodology for Construction Projects.", International Journal of Project Management, vol. 16, no. 4, pp. 215-21, 1998.

[28] L. Wang, "Enhancing construction quality inspection and management using RFID technology ", Automation in Construction - ELSEVIER, vol. 17 , no. 4, pp. 467-479, 2008.

[29] A. David, H.M. Gunaydin, "Total Quality Management in the Construction Process.", International Journal of Project Management, vol. 15 , no. 4, pp. 235-43, 1997.

[30] S. Ganesan, "Construction Productivity ", Habitat INTL, vol. 8, pp. 2942,1984

[31] C. Poon, A. Yu, L. Jaillon, "Reducing Building Waste at Construction Sites in Hong Kong ", Construction Management and Economics, vol. 22, pp. 461-70, 2004.

[32] D. Garrett, L. Lee, "Lean Construction Submittal Process.", Quality Engineering, Taylor \& Francis, vol. 23, pp. 84-93, 2011.

[33] A.R. Lapinski, J.H. Michael, R.R. David, "Lean Processes for Sustainable Project Delivery", ASCE, vol. 132, 2006.

[34] F. Pasqualini, P.A. Zawislak, "Value Stream Mapping in Construction: A Case Study in a Brazilian Construction Company", in Supply Chain Management-International Group for Lean Construction, Sydney, pp. $117-25,2005$.

[35] Y. Haitao, T. Tweed, M. Al-Hussein, R. Nasseri, "Development of Lean Model for House Construction Using Value Stream Mapping.", Journal of Construction Engineering and Management, vol. 135, no. 8, pp. 78290, 2009.

[36] B. Melissa, R. Ries, H.S. Matthews, A.L. Sharrard, "Example of a Hybrid Life-Cycle Assessment of Construction Processes" ASCE , 2006.

[37] M. Bilec, R. Ries, H. Matthews, "Life-Cycle Assessment Modeling of Construction Processes for Buildings.", Journal of Infrastructure Systems, vol. 16, no. 3, pp. 199-205, 2010

[38] G.A. Acree, A. Horvath, "Comparison of Environmental Effects of Steel- and Concrete-Framed Buildings.", Journal of Infrastructure Systems, vol. 11, no. 2, pp. 93-101, 2005.

[39] A. Sharrard, H. Matthews, R. Ries, "Estimating Construction Project Environmental Effects Using an Input-Output-Based Hybrid Life-Cycle Assessment Model.", Journal of Infrastructure Systems, vol. 14, no. 4, pp. 327-36, 2008

[40] L. Xiaodong, Y. Zhu, Z. Zhang, "An Lca-Based Environmental Impact Assessment Model for Construction Processes.", Building and Environment, vol. 45, no. 3, pp. 766-75, 2010.

[41] S. Han, M. Chae, K. Im, H. Ryu, "Six Sigma-Based Approach to Improve Performance in Construction Operations.", Journal of Management in Engineering, vol. 24, no. 1, pp. 21-31, 2008.

[42] L. Pheng, M. Hui, "Implementing and Applying Six Sigma in Construction.", Journal of Construction Engineering \& Management, vol. 130, no. 4, pp. 482-89, 2004.

[43] A. Stewart, A. Spencer, "Six-Sigma as a Strategy for Process Improvement on Construction Projects: A Case Study.", Construction Management \& Economics, vol. 24, no. 4, pp. 339-48, 2006.

[44] U.S. Environmental Protection Agency, "Tool for the Reduction and Assessment of Chemical and Other Environmnetal Impacts (TRACI)“, Cincinnati, Ohio, 2010

[45] R. Frischknecht, G. Rebitzer, "The ecoinvent database system: a comprehensive web-based LCA database.", Journal of Cleaner Production, vol. 13, no. 13-14, pp. 1337-1343, 2005. 
[46] Swiss Centre for Life Cycle Inventories, ecoinvent database ecoinvent centre, 1997.

[47] Sylvatica, G. A. N., The Franklin US LCI library, 2004. 


\section{SUPPLEMENTARY INFORMATION}

SI- 1. Final check sheet shows four major causes for painting blistering found via field examination

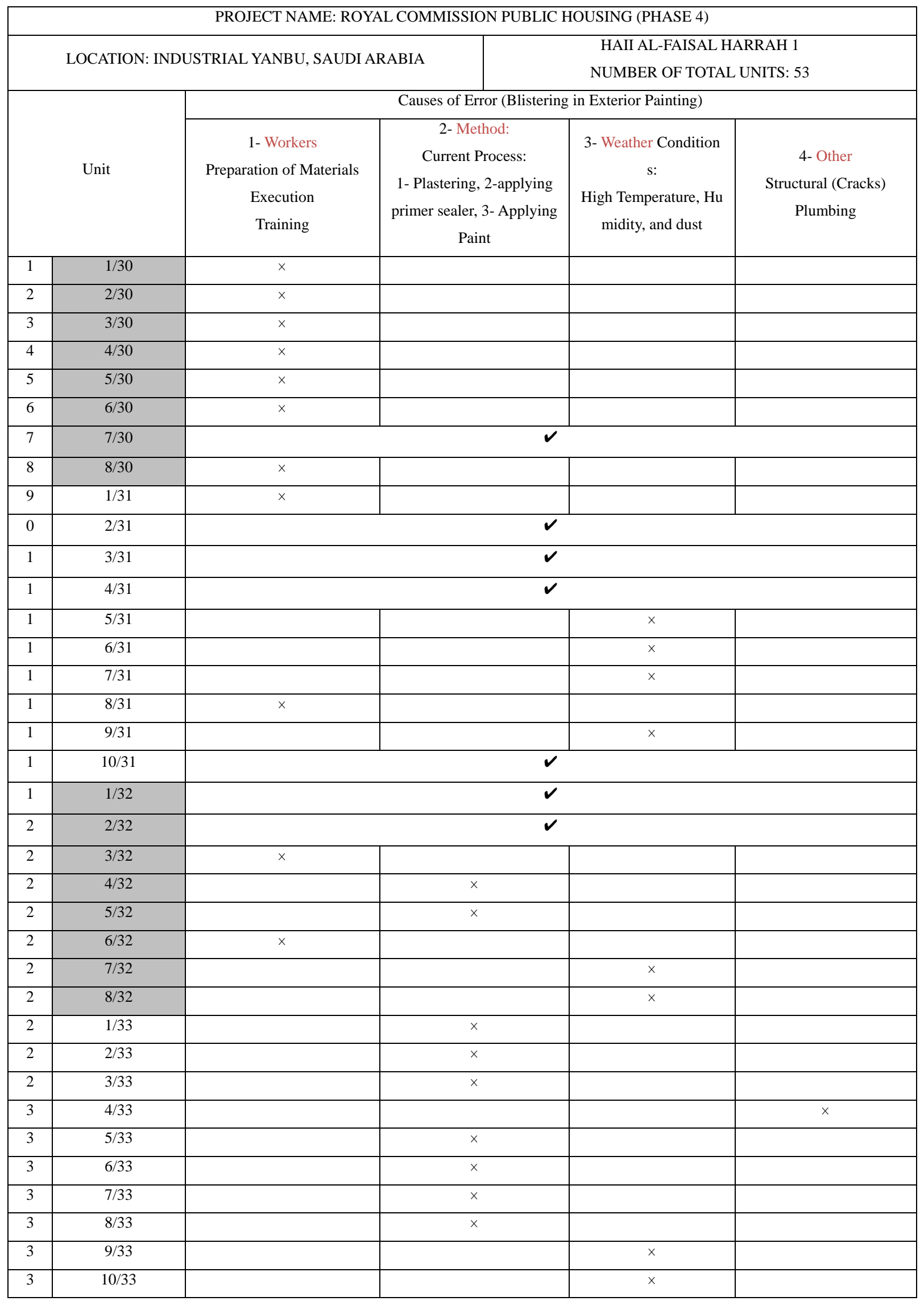




\begin{tabular}{|c|c|c|c|c|c|}
\hline 3 & $11 / 33$ & $x$ & & & \\
\hline 3 & $12 / 33$ & $x$ & & & \\
\hline 3 & $13 / 33$ & & & & $x$ \\
\hline 4 & $15 / 33$ & \multicolumn{4}{|c|}{$\boldsymbol{v}$} \\
\hline 4 & $17 / 33$ & \multicolumn{4}{|c|}{$\boldsymbol{v}$} \\
\hline 4 & $1 / 34$ & & $x$ & & \\
\hline 4 & $2 / 34$ & & $x$ & & \\
\hline 4 & $3 / 34$ & & & & $x$ \\
\hline 4 & $4 / 34$ & & $x$ & & \\
\hline 4 & $5 / 34$ & & $x$ & & \\
\hline 4 & $6 / 34$ & & $x$ & & \\
\hline 4 & $7 / 34$ & & $x$ & & \\
\hline 4 & $8 / 34$ & & $x$ & & \\
\hline 5 & 9/34 & & $\times$ & & \\
\hline 5 & $10 / 34$ & & $x$ & & \\
\hline 5 & $11 / 34$ & \multicolumn{4}{|c|}{$\checkmark$} \\
\hline 5 & $12 / 34$ & \multicolumn{4}{|c|}{$\boldsymbol{v}$} \\
\hline & Defects & 13 & 18 & 8 & 3 \\
\hline \multicolumn{5}{|c|}{ Total Number of Defects } & 42 \\
\hline \multicolumn{5}{|c|}{ Total Number of Checks } & 11 \\
\hline \multicolumn{5}{|c|}{ Total Number of checks/Opportunities for defects } & 53 \\
\hline \multicolumn{5}{|c|}{ Defective Per Million Opportunities (DPMO) } & 792,453 \\
\hline \multicolumn{5}{|c|}{ Six-Sigma level } & 1 out of 6 \\
\hline
\end{tabular}

